\title{
A DESJUDICIALIZAÇÃO COMO FORMA DE PROMOÇÃO DO ACESSO À JUSTIÇA NO BRASIL
}

\author{
Camilla Martins Mendes Pereira*
}

\begin{abstract}
RESUMO: A pesquisa trata da aproximação entre as políticas públicas de desjudicialização e o acesso à justiça. Objetiva-se demonstrar que a ampliação dos instrumentos que propiciem a garantia de direitos é uma etapa importante na democratização do acesso à justiça. Na realização do objetivo proposto nesta pesquisa utilizou-se como método de abordagem o dedutivo, quanto ao método de procedimento aplicado, elegeu-se a pesquisa teórica. Observa-se que a ampliação do acesso à justiça é salutar na concretização dos direitos dos cidadãos, contudo, apesar das alterações já promovidas no sistema brasileiro, ainda se encontram entraves ao acesso à uma ordem jurídica justa.
\end{abstract}

PALAVRAS-CHAVES: Desjudicialização; Acesso à Justiça; Políticas Públicas; Efetividade; Jurisdição.

\section{DEJUDICIALIZATION AS A WAY TO PROMOTE ACCESS TO JUSTICE IN BRAZIL}

\begin{abstract}
The research deals with the approach between dejudicialization and the access to Justice. The objective is to demonstrate that the expansion of the instruments that provide for the guarantee of rights is an important step in the democratization of access to justice. To carry out the objective proposed in this research was used the deductive hypothetical method, and the theoretical research. It is observed that the expansion of access to justice is healthy in the realization of citizens' rights, however, despite the changes already promoted in the Brazilian system, there are still obstacles to access to a fair legal order.
\end{abstract}

KEYWORD: Dejudicialization; Access to Justice; Public Policy; Effectiveness; Jurisdiction.

\footnotetext{
* Mestre em Direito Público pela Faculdade de Direito da Universidade Federal de Uberlândia. E-mail: camillammp22@gmail.com.
} 


\section{INTRODUÇÃO}

O direito e a justiça na contemporaneidade perpassam por processos de transformações influenciados pelo impacto da globalização, pela jurisdificação das relações sociais e pelo pluralismo jurídico. Essas ocorrências aliadas a problemas estruturais dos tribunais brasileiros, por exemplo, gestão e alocação dos recursos financeiros e humanos, têm impactado na crise da Justiça, caracterizada pela morosidade habitual, excesso de litígios e perda de credibilidade do Judiciário.

Este cenário demanda a retomada dos debates sobre a problemática do acesso à justiça, uma vez que este constitui importante instrumento de apropriação e reivindicação de novos e velhos direitos. De tal modo que, os percalços sofridos pelo sistema judicial são problemas que afetam não só o Poder Judiciário, mas a própria estrutura da democracia.

Observa-se recentemente a tendência de processos de desjudicialização, que exsurgem como alternativas à crise da Justiça assinalada. Nesta pesquisa, compreende-se a desjudicialização como o processo que envolve a ampliação de novas arenas para a discussão dos conflitos sociais. A proposição assemelha-se em vários aspectos com a implementação do sistema multiportas, que prevê a existências de vários modelos de soluções de conflitos para além do processo judicial.

Nesse sentido, a pesquisa trata da aproximação entre a desjudicialização e acesso à justiça. Questiona-se num primeiro momento o modelo atual de administração da justiça, fundado sob o dogma do monopólio estatal de gerir os conflitos sociais. Posteriormente, passase à análise da descentralização da administração da justiça e dos núcleos de solução de conflitos, com maior aproximação da sociedade na administração da justiça. Aspectos que envolvem inclusive a transferência de competência para a resolução de conflitos para instâncias alternativas ou para novas ou velhas profissões jurídicas. Para a realização dos objetivos propostos utiliza-se como método de abordagem dedutivo. No que tange ao método de procedimento aplicado, utiliza-se da pesquisa teórica.

\section{JUDICIALIZAÇÃO E DESJUDICIALIZAÇÃO DOS CONFLITOS}


A sociedade atual é considerada como sendo permeada pelo fenômeno da “juridificação das relações sociais", compreendido como a "colonização" ou "invasão" da vida pelo Direito, (GALANTER,1993, p. 103). De acordo com Viana, Burgos e Salles (2007), os conflitos sociais também passam a ser afetados por esse processo, resultando, mais das vezes na busca pelo Judiciário a fim de solucioná-los, o que propicia o chamado boom da litigação. Nesse sentido, identifica-se como um dos elementos da juridificação, a chamada judicialização, em que os problemas de ordens diversas acabam sendo discutidos no sistema judicial.

Como reflexo disso, vive-se assim uma situação paradoxal: (PEDROSO, 2011. p.37): "Por um lado, avança a "juridificação" e a "judicialização" da vida em sociedade, com a expansão do direito a outras áreas da sociedade e com a chegada de "novos" litígios oriundos da sociedade ou do mercado a tribunal". Por outro lado, paralelamente a esse processo, verificase de modo crescente o incentivo a um movimento que se passou a identificar como desjudicialização. Esse paradoxo é característico do direito pós-moderno, que não mais se apresenta numa visão monista apenas como o direito estatal. Nesse contexto, o pluralismo jurídico, a complexidade das sociedades contemporâneas e os novos conflitos e o volume numérico de processos no sistema judicial contribuem para desafiar o monopólio estatal da Justiça.

No que se refere à concepção de jurisdição focada eminentemente no aparelhamento estatal, o modelo tradicional passa a ser revisto para ser contemplada uma "pluralidade judicial", como reconhecimento de formas alternativas de resolução de litígios, sejam privadas, administrativas ou comunitárias e a configuração de uma "jurisdição compartilhada" (MANCUSO, 2014).

Nessa perspectiva, os percalços sofridos pela justiça oficial têm levado a alterações no sistema judicial nacional. Há uma maior tendência à desjudicialização dos conflitos por meio da crescente disposição de modelos alternativos de solução de conflitos. Isso sugere que, o próprio sistema jurídico tem desenvolvido mecanismos de forma a disponibilizar e incentivar o uso destes métodos, seja pela autocomposição (mediação; conciliação) ou heterocomposição (arbitragem) ou vias híbridas.

As discussões sobre a desjudicialização se inserem num contexto mais amplo, que envolve tanto a problemática do acesso à justiça e do tratamento dado pelo Estado aos diversos conflitos sociais, quanto da crise que perpassa o sistema jurídico e judicial. De modo que, para melhor compreender este debate faz-se necessário o estudo dos meandros que envolvem a questão da acessibilidade à justiça. Assim, para melhor contextualizar a temática discutida 
pretende-se analisar como ponto inicial o acesso à justiça como um fenômeno mais amplo, no qual se inserem as reformas da justiça numa tentativa de reformulação desta. A desjudicialização se apresenta nesse contexto como parte do discurso do processo democratizante de acessibilidade à Justiça.

\section{CONSIDERAÇÕES SOBRE O MOVIMENTO PELO ACESSO À JUSTIÇA}

Sob o pálio da terminologia de "acesso à Justiça" insere-se uma gama de questões, que vão desde aspectos relacionados ao exercício da cidadania e ao constitucionalismo, às barreiras que impedem a acessibilidade ao sistema jurídico. Enquadra-se nessa análise também, os métodos de resolução de conflitos judiciais e extrajudiciais, bem como diz respeito também à preocupação para com os resultados obtidos nesses procedimentos, se estes são justos, efetivos e se foram obtidos num lapso temporal razoável.

Inicia-se o debate pelo uso expressão "acesso à justiça", que é de difícil definição, pois permite inserções quanto aos aspectos políticos, econômicos e sociológicos sobre o tema Conforme pondera Kim Economides (1997), o problema é “[...] definir a que realmente queremos dar acesso aos cidadãos. Acesso a quê?” (ECONOMIDES, 1997, p.62). Nesse contexto, a discussão a que se pretende parte da análise proposta por Mauro Cappelletti e Bryant Garth nas décadas de 1960 e 1970.

Os juristas supracitados empreenderam no período referido, uma pesquisa empírica conhecida mundialmente como "Projeto Florença de Acesso à Justiça". O objetivo deste projeto era analisar as reformas processuais nos sistemas jurídicos em diversos Estados. Para tanto, a iniciativa, financiada pela Fundação Ford, contava com a participação de pesquisadores de diferentes nacionalidades, os quais formulavam relatórios sobre os sistemas jurídicos de seu respectivo país. Posteriormente, o resultado da pesquisa comparativa de quatro anos, viria a ser compilado no Relatório Geral "Access to Justice: the newest wave in the Worldwide movement to make rights effective" e ulteriormente traduzido para a versão em português como "Acesso à Justiça".

Conforme dados do relatório, Cappelletti e Garth (2002) verificam, num primeiro momento, que as formas de solução de conflitos refletiam a ótica individual-liberalista do século XVIII e XIX, e o acesso traduzia-se como o mero direito de petição formal aos tribunais. Não havia à época questionamentos quando à dificuldade na materialização desse direito, como por exemplo, no que tange à capacidade de reconhecimento dos direitos e da violação destes ou os altos custos da justiça, uma vez que sob os auspícios do liberalismo burguês não era 
necessária a proteção do Estado, que deveria apenas resguardar de modo passivo a acessibilidade ao sistema judicial.

Neste período, tem-se a conformação da figura do Estado Liberal, também denominado de Estado mínimo, pois foi fundado na concepção de que não cabia ao poder público interferir na esfera de ingerência da sociedade civil para garantir direitos. Caracterizavam-se aqui as chamadas liberdades negativas, onde os ideais de liberdade e igualdade propalados pela Revolução Francesa no século XVIII eram garantidos apenas em termos formais.

Com o advento da Revolução Industrial e as mazelas sofridas pelo proletariado surgem movimentos de reivindicação da igualdade material e não meramente formal. Afinal, como bem declara Bonavides (2013): “O velho liberalismo na estreiteza de sua formulação habitual, não pôde resolver o problema essencial de ordem econômica das vastas camadas proletárias da sociedade, e por isso entrou irremediavelmente em crise.” (BONAVIDES, 2013, p.188). Nessa perspectiva, o Estado é chamado a interferir cada vez mais em questões sociais ampliando as suas funções e, consequentemente, é levado a intervir mais na sociedade e no Direito ${ }^{\dagger}$. Como reflexo disso, há então a implementação do Estado Social, marcado pela elaboração de políticas sociais pelo poder público, bem como pela previsão de uma carga de direitos fundamentais nas constituições de segunda dimensão, que correspondem aos direitos sociais, econômicos e culturais.

É na segunda metade do século passado, no contexto do Estado Social, que ganha importância a relação entre a garantia de efetividade de direitos individuais e sociais com a possibilidade de reivindicação destes perante os sistemas judiciais. Como descreve João Antônio Fernandes Pedroso (2011), “O acesso ao direito e à justiça é, consequentemente, uma questão que faz sentido dentro de um Estado social, ou melhor, é um dos problemas básicos do cidadão do Estado social.” (PEDROSO, 2011, p. 85). Na medida em que os direitos sociais visam a materialização da igualdade, de modo a minimizar os danos negativos causados pelo mercado, o que propicia a realização da justiça social. Isso significa que, garantir o valor fundamental de acesso à justiça é garantir aos cidadãos a reivindicação e obtenção de direitos, o que gera a democratização das relações sociais entre os cidadãos e o Estado.

\footnotetext{
† Leciona Hespanha (2012): “Ao Estado, cada vez são pedidas mais tarefas, de fomento, de educação, sanitárias, de cadastro e de registro, de proteção social, de regulamentação do trabalho. Tudo isto requer - justamente! - mais administração pública, mais recursos fiscais, mais funcionários, mais regulamentos, mais invasão da vida quotidiana. Talvez não tanto naqueles aspectos cruciais das liberdades que os secs. XVII e XVIII tinham identificado, mas em coisas, tão comezinhas, como quotidianas e enervantes, como o requerimento, a selagem, a vistoria, o registro, etc." (HESPANHA, 2012, p.359)
} 
Há aqui a constatação da possibilidade de conversão da Justiça Cível em Justiça Cívica, uma vez que a garantia de acesso efetivo permite a reivindicação dos demais direitos (ECONOMIDES, 1997). Em função disso, a administração da justiça e o próprio processo não devem ser considerados apenas em sua dimensão formal e tecnicamente neutra, mas como instrumentos de realização de escopos sociais e políticos (DINAMARCO, 2009). Daí, afirmarse que: "O acesso à justiça pode, portanto, ser encarado como o requisito fundamental - o mais básico dos direitos humanos - de um sistema jurídico moderno e igualitário que pretenda garantir, e não apenas proclamar os direitos de todos.” (CAPPELLETTI; GARTH, 2012, p.21).

\subsection{Projeto Florença de acesso à justiça}

Mauro Cappelletti e Bryan Garth (2002) tomam como ponto de partida da pesquisa a identificação das barreiras que impossibilitam a acessibilidade. Dentre os problemas encontrados, num primeiro momento, destaca-se o alto custo no patrocínio da demanda. Afirmam os referidos autores que a falta de agilidade para que se obtenha uma decisão é um dos fatores que encarecem ainda mais o processo. Para além dos custos, identificam problemas com relação à "possibilidade das partes". Esse quesito perpassa pela situação financeira dos envolvidos na relação conflituosa e está intimamente relacionado à capacidade de reconhecer um direito e agir a partir deste conhecimento. Conforme destaca Maria Tereza Aina Sadek (2014), "Pesquisas comparativas internacionais mostram que sociedades marcadas por elevados índices de desigualdade econômica e social apresentam alta probabilidade de que amplas camadas de sua população sejam caracterizadas pelo desconhecimento de direitos." (SADEK, 2014).

O terceiro problema identificado no relatório elaborado por Cappelletti e Garth (2002) é com relação aos interesses difusos ou coletivos, tais como direito do consumidor ou meio ambiente equilibrado. Nesses casos, a demanda individual, quando possível com relação ao quesito da legitimação passiva, costuma ser inviável pela própria natureza do interesse em jogo. Afinal, como esclarecem os autores: "O problema básico que eles apresentam - a razão de sua natureza difusa - é que ninguém tem direito a corrigir a lesão a um interesse coletivo, ou o prêmio para qualquer indivíduo buscar essa correção é pequeno demais para induzi-lo a tentar uma ação.” (CAPPELLETTI; GARTH, 2002, p. 10). Além disso, devido à dificuldade prática de se organizar uma demanda coletiva é comum nos ordenamentos estabelecer-se a 
responsabilidade de sua proteção ao Estado, como por exemplo, no caso brasileiro, relega-se como uma das atribuições constitucionais do Ministério Público a tutela ambiental.

Diante desses problemas, é que os juristas desenvolveram a metáfora das três ondas renovatórias da justiça, as quais tratam das abordagens aplicadas pelos países participantes do projeto, na tentativa de corrigir o problema da efetividade do acesso à justiça. O primeiro viés abordado foi o do acesso aos tribunais pelas populações economicamente incapazes de sustentar os gastos com um processo. Cappelletti e Garth (2002) caracterizam essa fase como sendo a primeira onda do acesso, a saber, a assistência judiciária gratuita às populações carentes.

A segunda onda de reforma se dá com a representação dos interesses difusos. Observase que o modelo tradicional de processo focado na relação triangular entre autor, juiz e réu e na solução individual de interesses era incapaz de solucionar problemas de ordem coletiva. Nesse sentido, segundo Cappelletti e Garth (2002), identifica-se o movimento de reforma no intuito de modificar a relação individualista em prol de um processo social e coletivo.

A terceira onda, por sua vez, é a mais ampla dentre as três, sendo denominada, portanto, como "o enfoque do acesso à Justiça" (CAPPELLETTI; GARTH, 2002, p. 25). Ela envolve não só a justiça formal, mas também na chamada "justiça informal" ou métodos alternativos de solução de conflitos, como caminho não só de se abarcar os interesses que estavam sendo mal representados nas duas ondas anteriores, mas também para incluir aqueles que não tinham representação alguma.

Como reflexo disso, a terceira onda não exclui as reformas anteriores. Entretanto, não se elide da agenda deste "enfoque do acesso à justiça" a modernização e reformas de simplificação do processo judicial, contudo esta concentra-se sobretudo na tentativa de "desviar os litígios dos tribunais" (CAPPELLETTI; GARTH, 2002, p.33). De modo que, é nesta terceira onda que floresce a proposta da informalização por meio de métodos alternativos de solução de conflitos.

\subsection{Acesso à justiça no Brasil}

No Estado brasileiro pode-se identificar duas vertentes da processualística brasileira como resposta à crise da administração da justiça, as quais são denominadas de "deformalização do processo" e "deformalização das controvérsias". (GRINOVER, 2014, p. 35). No primeiro caso, segundo Ada Pellegrini Grinover (2014), utiliza-se da “[...] técnica processual em busca de um processo mais simples, rápido, econômico, de acesso fácil e direto, apto a solucionar 
com eficiência tipos particulares de conflitos de interesses." (GRINOVER, 2014, p. 35). Por sua vez, conforma a mesma autora, a "deformalização das controvérsias" diz respeito à busca por vias alternativas ou equivalentes jurisdicionais a fim de se evitar o processo judicial.

Cumpre notar, no entanto, que os moldes em que se desenvolvem as reformas no direito brasileiro não correspondem exatamente às analisadas no relatório geral "Acesso à Justiça". Aliás, muito embora o "movimento pelo acesso à justiça" se dê na década de 1970 em grande parte dos países ocidentais, no Brasil as produções sobre o tema por pesquisadores se dão somente na década de 1980.

De fato, o país não participou do Projeto Florença, de modo que não há um relatório sobre o sistema judicial nacional. Tal ausência é algo significativo, ainda mais quando outros países da América Latina, tais como Chile, Colômbia Uruguai e México participaram. Sobre os possíveis motivos da não participação brasileiro no mencionado Projeto pondera Eliane Botelho Junqueira (1996):

A não participação do Brasil no Florence Project teria sido resultado de dificuldades
de contatar pesquisadores brasileiros interessados em analisar esta questão? Ou seria
decorrente da falta de interesse dos nossos pesquisadores na segunda metade dos anos
70, já que o assunto é introduzido no cenário acadêmico e político brasileiro a partir
do final daquela década, quando (e aqui não coincidentemente se inicia o processo de
abertura política)? (JUNQUEIRA, 1996, p. 01).

Não há como se saber ao certo as razões para a ausência brasileira no projeto Florença. Contudo, ainda que no país tenham sido feitas reformas com relação à informalização do processo e a inserção de institutos que tratassem dos direitos difusos e coletivos pode-se deduzir que as razões para tais reformas são diferentes em relação aos países centrais.

O fundamento para esta proposição reside na diferença entre o contexto em que surge o movimento pelo acesso aqui e em países europeus ou nos Estados Unidos. Em países centrais, este se dá num Estado de bem-estar social que já estava moderadamente consolidado e há a busca de uma minoria por efetivação de direitos básicos. Já no Brasil, esse processo se distorce, uma vez que não se chega a consolidar o Welfare State e há uma maioria extensa da população que não tem concretizados os seus direitos individuais, políticos, sociais ou coletivos (CAPILONGO, 2010).

Como explica Celso Campilongo (2010):

Nos países centrais, a contextualização do acesso à justiça vem precedida por um processo histórico e cumulativo de afirmação da eficácia dos direitos: em primeiro lugar, os direitos civis ou individuais; em segundo lugar, os direitos políticos; e, finalmente, os direitos sociais. Uma sequência, cada uma dessas etapas sendo precedida de uma relativa consolidação da eficácia da etapa anterior. Entre nós, o 
processo se dá de uma forma completamente diversa. Nós tentamos simultaneamente, na mesma conjuntura histórica, afirmar tanto os direitos civis e individuais quanto os direitos políticos, os direitos sociais e os coletivos. Ou seja, os desafios para o acesso à justiça entre nós são infinitamente mais acentuados (CAMPILONGO,2010, p.15).

Ainda como o autor retrata, a preocupação naqueles países é a preservação de certos direitos, que estavam sob ameaça diante da crise do Estado de bem-estar social. Já no Brasil, não se pretende a preservação, mas a obtenção de direitos que não se tinham antes, por meio de algo inédito na história do país, a saber, "[...] a afirmação da cidadania pela via judicial" (CAMPILONGO, 2010, p.15).

Desta forma, a preocupação central na década de 1980 não era a efetivação de direitos pela via judicial como em países europeus, nem mesmo desafogar o Judiciário nacional por meio da via da justiça informal, devido a uma explosão de litígios em razão da busca de efetividade de direitos fundamentais (principalmente direitos sociais normatizados durante o Welfare State). Aqui, voltava-se a atenção para a redemocratização do Estado e reabertura política, bem como para os movimentos sociais, que eclodiram no período e a demanda por instrumentos capazes de resolvê-los (JUNQUEIRA, 1996).

De modo que, muitos pesquisadores brasileiros, principalmente sob influência do desenvolvimento da sociologia jurídica no país, voltam-se para o tema do pluralismo jurídico e os meios de resolução de conflitos. Estas pesquisas receberam ao período forte influência do trabalho empírico de Boaventura de Sousa Santos, que analisou a estrutura jurídica na favela do Jacarezinho no Rio de Janeiro, a qual denominou ficticiamente de Pasárgada. Constata o autor, conforme Junqueira (1996), que os obstáculos ao acesso ao direito estatal nesta comunidade corroboraram para o surgimento de um direito não oficial e de formas de solução de conflitos informais.

O debate sobre a efetividade de direitos fundamentais no Brasil por meio da via judicial se daria em momento posterior. É com a redemocratização e a promulgação da Constituição Federal de 1988, em que se passa a observar um aumento considerável de ações nos tribunais nacionais, principalmente relacionadas à concretização de direitos sociais, tais como saúde e educação.

Nesse contexto, salienta Boaventura que a implementação de novos direitos fundamentais “[...] tende a aumentar as expectativas dos cidadãos de verem cumpridos os direitos e as garantias consignadas na Constituição, de tal forma que a execução deficiente ou inexistente de muitas políticas sociais pode transformar-se num motivo de procura dos tribunais." (SANTOS, 2011, p. 11). 
Ademais, é, igualmente, no ano de 1988 que se traduz para o português a versão resumida da obra "Acesso à Justiça” de autoria de Cappelletti e Garth, a qual viria a influenciar vasta gama dos trabalhos e pesquisas sobre o tema. E é mais recentemente, especificamente após a criação do Conselho Nacional de Justiça em 2004, que se tem focado em reformas relacionas à terceira onda, especialmente por meio da introdução de mecanismos que visem desafogar a via judicial, por meio da implementação de vias alternativas.

Entretanto, apesar das transformações promovidas pela Constituição de 1988 e as recentes alterações legislativas em matérias processuais. A temática do acesso à justiça permanece premente, no cenário jurídico nacional. Afinal, a problemática da efetivação de direitos sociais é mais atual do que nunca, frente às transformações econômicas e políticas e a influência neoliberal.

\section{MOVIMENTO PELA DESJUDICIALIZAÇÃO E A CONSTRUÇÃO DE UM NOVO MODELO DE ADMINISTRAÇÃO DA JUSTIÇA}

O acolhimento pelo Estado da pacificação social por meio da resolução dos conflitos surgidos no bojo da sociedade com a vedação à chamada "justiça com as próprias mãos" ou autotutela $^{19}$, é um processo que se fortalece com a configuração do Estado de Direito no século XIX. Este sistema, conforme assinala Mancurso (2014), se consolida com a aclamação dos direitos fundamentais, em especial os direitos sociais, que criam para o Estado a obrigação positiva de prestar à sociedade as garantias previstas nas Constituições.

Entretanto, o acolhimento pelo Estado da função precípua de resolução de litígios não foi seguido por um bom sistema de gestão da crescente massa numérica de processos. Como pode ser percebido até o momento, e conforme os dados apresentados pelo Conselho Nacional de Justiça ${ }^{\ddagger}$, as demandas geradas pela sociedade contemporânea vão muito além da capacidade do aparato estatal. A busca por novos direitos ou a procura pela efetivação de direitos garantidos meramente no âmbito formal ${ }^{\S}$ tem desencadeado novos conflitos sociais

\footnotetext{
* Dados colhidos pelo relatório Justiça em número.

$\S$ O autor determina que esses direitos “[...] no âmbito das instituições periféricas latinas (caso do Brasil), afirmamse como básicos para a própria sobrevivência de grandes parcelas da população. As demandas por direitos cobrem largo espectro de necessidades e privações exigências que alcançam o direito à água, saúde, saneamento, assistência médica; o direito de igualdade para a mulher, o direito à creches para as mães que trabalham; bem como o direitos dos índios às suas terras, o direito das minorias étnicas, o direito de proteção às crianças exterminadas
} 
(WOLKMER, 2001). Tais fatores demonstram a necessidade de reformular e melhorar a política nacional de tratamento adequado dos conflitos.

O modelo contemporâneo de administração da justiça se assenta ainda quase que completamente no monopólio estatal de solução de conflitos por meio dos tribunais judiciais. Nesse sentido, parte da crise presenciada pela justiça oficial residiria no fundamento de confiar que a prestação jurisdicional seja sozinha capaz de dizer o direito de forma eficaz e adequada aos diversos casos apresentados na sociedade atual, cada vez mais complexa e plural. Como reflexo disso, cresce o incentivo a uma nova vertente, em que a noção de jurisdição se desconecta do conceito tradicional como função, atividade e poder do Estado, para abranger concepção mais ampla, para admitir instituições e formas de resolução para além das contempladas no sistema judiciário nacional.

A essa concepção de "jurisdição compartilhada" entre o poder público e entidades não estatais se coaduna com as percepções das transformações pelas quais passa o direito atual (INDA, 2001). Caminha-se em direção a um pluralismo jurídico, necessitando-se que se reforme também o conceito de jurisdição como monopólio do Estado, para que se concretize a pluralidade de métodos e instâncias de solução de conflitos e consequentemente promova a democratização do acesso à justiça.

Por sua vez, como visto anteriormente o acesso à justiça constitui-se importante instrumento democrático de garantia de direitos uma vez que viabiliza a efetivação de direitos fundamentais. Como consequência disso, a necessidade de ampliação de acesso constitui inevitavelmente a demanda por uma nova Justiça por meio de políticas públicas que reformulem o tratamento adequado aos conflitos. Neste modelo de Administração da justiça proposto por Pedroso se encaixa a definição de tribunal como "[...] a entidade que os litigantes considerem mais legítima e adequada para a resolução do seu conflito e defesa dos seus direitos. Essa entidade tanto pode ser o tribunal judicial como qualquer instância que cumpra essa finalidade.” (PEDROSO, 2011, p. 100).

A adoção efetiva deste sistema depende da reorganização dos papeis exercidos pela entidade Estatal e a sociedade civil. O que, para que se alcance este resultado necessariamente perpassa pelos caminhos da informalização e desjudicialização da justiça, que compreendem em sentido lato, “diferentes realidades que permitem prevenir ou resolver um litígio, ou seja, um conflito social que dois ou mais interessados pretendam que seja dirimido sem recurso

nas ruas e os direitos da população por proteção e segurança contra as diversas formas de violência. (WOLKMER, 2001, p. 92). 
ao tribunal judicial” (PEDROSO, 2002, p. 18).

A informalização está relacionada ao movimento pelos "meios alternativos de resolução de conflito" (MARC), do inglês alternative dispute resolution (ADR). Esse processo, em regra, é oriundo de movimentos que partem da sociedade, por exemplo, organizações sociais e econômicas. O fundamento reside na crítica aos moldes centralizados e estatais de resolução de conflitos e privilegiava métodos informais e descentralizados, focados na consensualidade e na maior participação das partes (PEDROSO, 2002). Vale lembrar que nos Estados Unidos tem-se um profícuo desenvolvimento de métodos alternativos e formas híbridas de solução de litígios. Contudo, ao contrário dos países europeus, o movimento de acesso à justiça neste país, segundo Cappelletti, “[...] não é visto ali como um 'direito social', mas antes como um 'problema social', do qual uma solução consiste em retirar dos tribunais boa quantidade de litígios." (CAPPELLETTI, 2014, p. 292).

A retomada das técnicas de resolução de conflitos "parajudiciais" ou "equivalentes jurisdicionais", comumente conhecidos como meios alternativos de resolução de conflitos (MARCs) ou meios extrajudiciais de resolução de conflitos (MERCs), representam uma reavaliação do conceito de jurisdição e uma tentativa de desafogo do Judiciário. Insta ressaltar que, preliminarmente, a doutrina processualística contemporânea considera a terminologia, "alternativo", inadequada, pois tal vocábulo configura os MARCs como sendo uma segunda opção, diante da incapacidade da jurisdição estatal tradicional de cumprir o seu papel. Convenciona-se a terminologia, "adequada", como sendo opção conveniente, pois trata-se de considerar qual o mecanismo mais pertinente para a solução de determinado conflito ${ }^{* *}$. Compreende-se, outrossim, que a utilização de métodos ou formas alternativas de resolução de conflitos não é nova, o que é diferente, segundo Pedroso (2002), é o modo como esse processo tem sido incentivado por legisladores e doutrinadores como forma alternativa, substitutiva ou complementar aos tribunais judiciais.

Por sua vez, a desjudicialização é estruturada no contexto do direito estatal e se apresenta como uma resposta à ineficiência dos tribunais no tratamento dos conflitos que lhes são dispostos, à morosidade na obtenção de um provimento final, e à dificuldade no acesso à justiça. A temática da desjudicialização é controversa e recente ${ }^{\dagger \dagger}$, uma vez que não

\footnotetext{
*** Contrário a esse posicionamento, Francisco José Cahali (2015) defende que a terminologia "alternativa" não tem a intenção de diminuir essas vias em relação ao Poder Judiciário.

† Como revela Almeida "Os estudantes da minha geração jamais poderiam pensar, naquelas décadas de sessenta e setenta, que veriam emergir uma força normativa a buscar exatamente o caminho inverso, a descentralização de parte das atividades jurisdicionais, ou seja, que setores da sociedade pudessem voltar a contribuir com a administração da Justiça, praticando atos que anteriormente eram reservados apenas aos Órgãos Judiciários, por
} 
há uma definição clara e específica sobre o termo e como se desenrola o fenômeno. Observase, por meio da análise de artigos e documentos sobre o tema, que a palavra é um neologismo, em regra, empregada na cultura jurídica atual, tanto pela doutrina quanto por membros do Judiciário, como uma reação à judicialização excessiva dos conflitos e também como uma tentativa de solucionar os problemas da morosidade e falta de eficiência da justiça oficial. (CAPPELLI, 2011).

Quanto aos caminhos para a realização de políticas de desjudicialização, pode-se observar várias vertentes. Em um primeiro momento tem-se a simplificação dos procedimentos judiciais e a utilização de meios consensuais (mediação; conciliação) dentro do rito processual. Ademais abre-se um leque de possibilidades quanto aos métodos de resolução de conflitos, configurando o chamado tribunal multiportas. Nesse contexto, a proposta aventada pela “desjudicialização" é a de construção de um novo modelo de Administração fundada na reforma do Judiciário e do sistema de justiça incluindo práticas alternativas de solução de conflitos. A proposição do autor é semelhante à proposta norte-americana, a saber, o sistema multiportas de solução de conflitos (do inglês Multidoor Courthouse System).

Originário do ordenamento norte americano na década de 1980, o sistema multiportas prevê a existência de várias possibilidades (portas) para a resolução das disputas trazidas ao Judiciário. A iniciativa foi apresentada inicialmente em 1976 pelo professor da Harvard Law School, Frank Sander, na conferência conhecida como The Pound Conference, conforme informam Sales e Sousa (2011). Neste modelo de Administração da justiça, as partes, em um primeiro momento, são orientadas pelo órgão jurisdicional sobre qual via de resolução adequada para determinado tipo de litígio. A indicação não é vinculativa, e tem a vantagem de possibilitar maior eficiência.

Defendem processualistas que, desde a resolução 125/2010 e com a promulgação do novo Código de Processo Civil no ordenamento nacional, pode-se considerar inaugurado no processo brasileiro o modelo de solução multiportas ${ }^{\dagger}$. Entretanto, a verdade é que há ainda longo caminho a ser percorrido na propagação deste modelo, a começar pelos próprios operadores do Direito.

meio de seus Juízes e auxiliares diretamente a eles ligados. A bem da verdade, esta tendência vem-se acentuando apenas recentemente, por meio de um fenômeno que se convencionou denominar "desjudicialização." (ALMEIDA, p.103, 2011).

\$ Cahali (2015) defende que com a implementação da resolução 125 do CNJ e a publicação do novo Código de Processo Civil inaugurou-se efetivamente o tribunal multiportas no país. 
As recentes alterações legislativas comprovam a tendência desjudicializante. $\mathrm{O}$ principal incentivo por esse processo de desjudicialização e informalização advém da própria comunidade jurídica, seja pela doutrina, ou pelo próprio poder Judiciário, sob influência do CNJ. Em contrapartida, a falta de conhecimento e familiaridade em relação a esses métodos é um ponto que dificulta o seu acesso pela população. Mesmo nas faculdades de direito do país a temática é recente. Pela análise curricular das principais faculdades de direito ${ }^{\S \S}$ já é possível verificar que a inclusão de disciplinas orientadas ao assunto é hodierna. Quando há tal previsão no currículo da graduação, nem sempre essa se encontra entre as disciplinas obrigatórias.

Verifica-se também a necessidade de remodelação das profissões jurídicas, devido à criação de novos ofícios como o do mediador ou conciliador familiar, e a atribuição de novos encargos a antigas profissões como notários (PEDROSO, 2002), que no ordenamento nacional, possuem a competência para a realização de divórcios e partilhas extrajudiciais pela via administrativa nos termos da Lei n. 11.441/2007.

Ainda, um segundo segmento deste processo se dá quando o conflito social deixa de ser judicializável, seja por processos de descriminalização ou desjuridificação, em que determinado assunto deixa ter relevância para o direito estatal. Outro percurso possível é por meio da transferência de competência para instituições "não judiciais", sejam essas privadas (conciliação, mediação, arbitragem), administrativas (comissões administrativas) ou híbridas, que passam a ser responsáveis pela resolução de litígios, ainda que em primeira instância (PEDROSO, 2002).

Por último, Pedroso identifica: “[...] a regulação dos conflitos sociais através da prevenção dos litígios com recurso a divulgação de informação jurídica [...]” (PEDROSO, 2002, p. 20). No Brasil alguns institutos têm sido facilitadores na prevenção de futuros litígios, como por exemplo, a recuperação extrajudicial de empresas (Lei 11.101/2005).

Como pode ser observado, os percursos da desjudicialização são amplos e nem sempre definidos. Entrementes, como consequência desse processo verifica-se a intensificação do debate no meio acadêmico e entre operadores do direito, bem como esforço de instituições particulares ou profissionais no desenvolvimento de vias adequadas ao tratamento dos conflitos. Ademais, dentre os inúmeros exemplos das iniciativas do CNJ e magistrados singulares, resta como fato marcante da desjudicialização no Brasil a condição de se desenvolver como uma

\footnotetext{
$\S \S$ Tendo como base o Ranking da Folha que divulgou a classificação de faculdades de Direito do país com base em critérios tais como avaliação do mercado, qualidade de ensino Doutorado e Mestrado, nota no Enade, professores com dedicação integral e parcial e avaliadores do MEC.
} 
política, principalmente no âmbito do poder Judiciário, ainda atrelado à noção do monopólio da jurisdição estatal por este poder e progride mediante um sistema hierarquizado.

Além disso, o programa de incentivo aos meios alternativos se desenvolve aliado à problemática da crise da justiça, representada na morosidade e ineficiência na solução de litígios. Mancuso (2014) considera que, "O notório crescimento - quantitativo e qualitativo dos meios alternativos se verifica em proporção inversa à perda de eficiência e prestígio do serviço estatal de distribuição da Justiça, comprometendo a credibilidade do Judiciário ao interno da coletividade." (MANCUSO, 2014, p. 235).

Santos, Marques e Pedroso (1995) entendem que, de fato, há um certo desvio de litígios dos tribunais para outras vias de resolução, ainda que seja questionável em termos quantitativos, e a própria atuação judicial acabou por impulsionar esse movimento, devido à morosidade e os custos da justiça estatal, que a tornou menos atrativa aos litigantes. Essa é justamente a crítica de Michelle Taruffo (2013) aos alternative dispute resolution (métodos alternativos de solução de conflitos). Para o autor italiano, esse sistema só é incentivado em países cujo sistema de justiça oficial é ineficiente, pois onde este sistema funciona adequadamente o uso da via alternativa ou complementar é marginal.

É importante considerar, nesse sentido, que para reformulação de um novo modelo de administração da justiça é necessário não só a implementação e a divulgação de modelos "parajudiciais", bem como é importante a implementação de um processo judicial adequado. Afinal, não há realmente equilíbrio entre as alternativas se nem todas elas se mostram aptas ou eficazes.-Mancuso adverte: "Portanto, tanto é insustentável (e discriminatória) a postura depreciativa em face dos meios alternativos - neles vislumbrados uma Justiça de segunda classe - como também o é a postura derrotista em face da Justiça estatal, apostando na sua débâcle irreversível." (MANCUSO, 2014, p. 274).

\section{CONSIDERAÇÕES FINAIS}

Na pesquisa desenvolvida ficou evidenciado que a crise do sistema judicial demanda a retomada de discussões sobre a acessibilidade à justiça, aqui compreendida em sentido amplo, como ingresso à tribunais ou instituições não estatais. As recentes transformações legislativas (lei de mediação, novo CPC, alterações na lei de arbitragem) promovem o enfoque da acessibilidade sob a perspectiva dos métodos extrajudiciais e adequados de solução de conflitos. 
O desafio deste processo de desjudicialização é a efetivação dos valores de justiça e democracia participativa, sem que se volte como instrumento de manipulação, em que a parte “mais capaz" se aproveite deste como forma de dominação do participante vulnerável. Ademais, que o discurso de fundamentação de um campo amplo de mecanismos de prevenção e composição de conflitos não tenha como base o descrédito ao Judiciário, mas sim a democratização do acesso a uma ordem justa e implementável.

Pode-se observar no decorrer da pesquisa que há um paradoxo, muito acesso para poucos, os chamados litigantes habituais, e muitos sem acessibilidade alguma, em que a falta de conhecimento em relação aos direitos é um dos principais motivos dessa deficiência, aspecto relacionado também a questões socioeconômicas. Nesse cenário, verifica-se a falta de conhecimento em relação aos direitos. De modo que, a preocupação com o acesso à justiça se inicia antes do ingresso efetivo ao sistema jurisdicional por meio de tribunais e instituições não estatais, perpassa pela fase anterior, envolve, portanto, a capacidade de reconhecimento dos direitos e a tomada de ação diante deste fato. Considera-se, assim, as vantagens de implementação de um sistema multiportas, que aproxime o cidadão do sistema de justiça e que apresente um leque de opções para a resolução adequada dos litígios, sem que os jurisdicionados sejam encaminhados obrigatoriamente para o processo judicial.

Contudo, ampliar o rol de possibilidades e métodos de prevenção e resolução de conflitos por si não é suficiente para incentivar o exercício à cidadania, devendo a mesma ser acompanhada por políticas públicas informacionais e educacionais, a fim de que o ingresso à justiça, aqui compreendido em sentido amplo, ou seja, não somente como acesso aos tribunais, seja efetivado.

Não adianta disponibilizar várias "portas" se não há a difusão do conhecimento sobre elas e de como cada qual pode contribuir na composição dos conflitos. A deficiência neste aspecto se inicia na própria formação do operador do Direito, quiçá poderá ser dito das grandes massas populacionais. Diante disso, ressalta-se a importância de um plano educacional associado à disposição de um tribunal multiportas.

\section{REFERÊNCIAS}

ALMEIDA, João Alberto de. Desjudicialização: a relação entre a arbitragem e os serviços notariais e registrais. Revista Faculdade de Direito UFMG, Belo Horizonte, n. 59, p. 101 a 122, jul./dez. 2011. 
BONAVIDES, Paulo. Do Estado Liberal ao Estado Social. $11^{\circ}$ ed. São Paulo: Malheiros, 2013.

CAHALI, Francisco José. Curso de Arbitragem: mediação, conciliação, resolução CNJ 125/2010. $5^{\text {a }}$ ed. São Paulo: Revista dos Tribunais, 2015.

CAMPILONGO, Celso. Apresentação realizada na Sessão "O Judiciário e o acesso à Justiça, In SADEK. Maria Tereza (org). O Judiciário em Debate. Rio de Janeiro: Centro Edelstein de Pesquisas Sociais, 2010. Disponível em: 〈http://books.scielo.org/id/82r9t >. Acesso em: setembro de 2020.

CAPPELLETTI, Mauro. Os métodos alternativos de solução de conflitos no quadro do movimento universal de acesso à justiça. Revista de Arbitragem e Mediação, vol. 41, p. 405 -423 , abr/jun. 2014.

CAPPELLETTI, Mauro; GARTH, Bryant. Acesso à Justiça. Tradução de Ellen Gracie Northfleet. Porto Alegre: Fabris, 2002.

CAPPELLI, Sílvia. Desformalização, Desjudicialização e Autorregulação: tendências no Direito Ambiental?. Revista de Direito Ambiental, vol. 63, p. 69 - 99, jul/set. 2011.

CONSELHO NACIONAL DE JUSTIÇA (Brasil). Resolução 125/2010. 2010. Disponível em: < https://atos.cnj.jus.br/atos/detalhar/156>. Acesso em: setembro 2020.

DINAMARCO, Cândido Rangel. $\boldsymbol{A}$ instrumentalidade do processo. $14^{\mathrm{a}}$ ed. São Paulo: Malheiros, 2009.

ECONOMIDES, Kim. Lendo as ondas do "Movimento de Acesso à Justiça": epistemologia versus metodologia?. Tradução Paulo Martins Garchet. Disponível em: $<$ http://gajop.org.br/justicacidada/wp-content/uploads/Lendo-as-Ondas-do-Movimento-deAcesso-aa-Justica.pdf >. Acesso em: setembro de 2016.

GALANTER, Marc. Direito em abundância: a atividade legislativa no Atlântico Norte. Revista Crítica de Ciências Sociais, vol. 36, p. 103-145, fev. 1993.

GRINOVER, Ada Pellegrini. Deformalização do processo e deformalização das controvérsias. Doutrinas Essenciais Arbitragem e Mediação. vol. 6, p. 33 - 64, set. 2014a.

HESPANHA, António Manuel. Cultura Jurídica Europeia: síntese de um milénio. Coimbra, Almedina, 2012.

INDA, Andrés García. Cinco apuntes sobre derecho y postmodernidad. Doxa - Cuadernos de Filosofía del Derecho. v.24, p. 05-39. 2001. Disponível em: < https://doxa.ua.es/article/view/2001-n24-cinco-apuntes-sobre-derecho-y-postmodernidad >. Acesso em: setembro de 2020.

JUNQUEIRA, Eliane Botelho. Acesso à Justiça: um olhar retrospectivo. Revista Estudos Históricos, Rio de Janeiro, v. 9, n. 18, p. 389-402, dez. 1996. ISSN 2178-1494. Disponível 
em: 〈http://bibliotecadigital.fgv.br/ojs/index.php/reh/article/view/2025>. Acesso em: 06 de setembro de 2020.

MANCUSO, Rodolfo de Camargo. A resolução dos conflitos e a função judicial no contemporâneo Estado de Direito. $2^{\circ}$ ed. São Paulo: Revista dos Tribunais, 2014.

PEDROSO João; TRINCÃO Catarina; DIAS João Paulo. E a justiça aqui tão perto? As transformações no acesso ao direito e à justiça. Revista Crítica de Ciências Sociais, n. 65, p. 77-106, maio, 2003. Disponível em: 〈www.ces.uc.pt/rccs/includes/download.php?id=818>. Acesso em: 20 de agosto de 2016.

PEDROSO, João. Acesso ao Direito e à justiça: um direito fundamental em (des)construção: o caso do acesso ao direito e à justiça da família e das crianças. 2011. 647 f. Tese (Doutorado em Sociologia do Estado, do Direito e da Administração). Faculdade de Economia, Universidade de Coimbra, Coimbra, 2011.

PEDROSO, João. Percurso (s) da (s) reforma (s) da administração da justiça - uma nova relação entre o judicial e o não judicial. Centro de Estudos Sociais, Observatório Permanente da Justiça Portuguesa, Coimbra, v. 171, p.1-43, abr. 2002. Disponível em: <http://www.ces.uc.pt/publicacoes/oficina/ficheiros/171.pdf>. Acesso em: 20 de agosto 2016.

SADEK, Maria Tereza Aina. Acesso à Justiça: um direito e seus obstáculos. REVISTA USP, São Paulo. n. 101. p. 55-66, março/abril/maio 2014. Disponível em:

<http://www.revistas.usp.br/revusp/article/view/87814>. Acesso em: 08 de agosto de 2020.

SALES, Lilia Maia de Morais; SOUSA, Mariana Almeida de. O sistema de múltiplas portas e o Judiciário brasileiro. Revista Direitos Fundamentais \& Justiça. Ano 5, no 16, p. 204-220, jul./set. 2011.

SANTOS, Boaventura de Sousa. Para Uma Revolução Democrática da Justiça. $3^{\text {a }}$ ed. São Paulo: Cortez, 2011.

SANTOS, Boaventura; MARQUES, Maria Manuel Leitão; PEDROSO, João. Os tribunais nas sociedades contemporâneas. Porto, Afrontamento, 1995.

TARUFFO, Michele. Un'alternativa alle alternative: modelli di risoluzione dei conflitti.. Argumenta Journal Law, Jacarezinho - PR, n. 7, p. 257-270, fev. 2013. ISSN 2317-3882. Disponível em: <http://seer.uenp.edu.br/index.php/argumenta/article/view/84>. Acesso em: 03 de agosto de 2020.

VIANNA, Luiz Werneck; BURGOS, Marcelo Baumann; SALLES, Paula Martins. Dezessete anos de judicialização. Tempo Social, Revista de Sociologia da USP, v. 19, n. 2, p 39-85.

São Paulo: FFLCH-USP, 2007. Disponível em:

<http://www.scielo.br/scielo.php?script=sci_arttext\&pid=S0103-20702007000200002>. Acesso em: 10 julho de 2020.

WOLKMER, Antônio Carlos. Pluralismo jurídico: fundamentos de uma nova cultura do direito. São Paulo: Alfa-ômega, 2001. 